\title{
PROPAGACIÓN SEXUAL Y ASEXUAL DE ÑIRE Nothofagus antarctica (Forster) Oerst. EN LA PATAGONIA CHILENA
}

\author{
Salinas, Jaime ${ }^{3}$; Koch, Laura; Acuña, Bernardo y Uribe, Alicia.
}

\section{RESUMEN}

La Región de Aysén se encuentra en el sur austral de Chile $\left(44^{\circ}-49^{\circ} \mathrm{LS}\right)$, es la tercera región más extensa del país y la que dispone de la mayor cubierta de bosques nativos. Dada su ubicación, su superficie y sus recursos forestales presenta una amplia variedad de ecosistemas y una rica biodiversidad acuática y terrestre, que le confieren grandes potenciales en ámbitos como el forestal y el turístico, entre otros atractivos.

Nothofagus antarctica (Forster) Oerst., ñire, es una especie endémica de los bosques templados lluviosos o subantárticos de Chile y Argentina, y presenta el rango de distribución más amplio de los Nothofagus sudamericanos. Su distribución en Chile abarca desde la precordillera andina de la región del Maule hasta el límite sur en Cabo Hornos, Región de Magallanes. Existen unas 500 mil hectáreas del Subtipo Forestal Ñire, dentro del Tipo Forestal Lenga (Nothofagus pumilio). En Argentina en tanto, crece en una amplia extensión en las cumbres de la cordillera de Los Andes, hasta el extremo sur en las riberas del canal Beagle. En la Patagonia Argentina se estima su cobertura en unas 750 mil hectáreas.

Ñire es una especie secundaria en cuanto a producción de madera, pero tiene una gran presencia en la Patagonia en Chile y en Argentina, conformando los bosques que llegan hasta el límite altitudinal, acompañando a lenga o constituyendo bosque puros a mayor altitud. Los principales usos de la especie están representados por madera para usos menores y leña, pero sus formaciones naturales son de gran importancia ambiental y paisajística, y para su uso integrado en combinaciones silvopastorales.

Dado que en la Región de Aysén existen extensas áreas de suelos desarbolados y de bosque degradados, producto de antiguos incendios y de desmontes para el uso agrícola o ganadero, la especie es de importancia para la repoblación y para la restauración de ecosistemas en esta región austral de Chile. Se trata de una especie de gran plasticidad para adaptarse a una variedad de condiciones de sitio, pero su semilla es de baja capacidad germinativa y esto limita su propagación en viveros. Esto ha motivado al Instituto Forestal, dentro de sus programas de investigación en bosque nativo, a iniciar una línea de trabajo orientada a las técnicas de propagación de esta especie, tanto por la vía sexuada a través de sus semillas como por la vía asexuada mediante propagación vegetativa.

En el presente trabajo se presentan los primeros resultados de la línea de trabajo indicada, resultados que por ahora no son muy alentadores. Se probaron en laboratorio distintos pretratamientos de semillas para romper su latencia y mejorar su capacidad germinativa, y tratamientos de estimulación de enraizamiento en invernadero para arraigamiento de estacas. La capacidad germinativa máxima obtenida en laboratorio con un tratamiento de estratificación fría húmeda de las semillas fue de $28 \%$ y en arraigamiento de estacas en invernadero se alcanzó a un $23 \%$ en respuesta de formación de raíces con un tratamiento de inmersión previa de estas en ácido indol butírico.

Palabras clave: Ñire, Nothofagus antarctica, pretratamiento de semillas, arraigamiento de estacas.

\footnotetext{
${ }^{3}$ Ingeniero Forestal. Investigador, Sede Patagonia INFOR. jsalinas@infor.cl
} 


\section{SUMMARY}

The Aysén region is located in southern Chile $\left(44^{\circ}-49^{\circ} \mathrm{LS}\right)$, is the third largest region in the country and has the largest native forest cover as well. The region presents a wide ecosystems variety and biodiversity richness, so that has also a great forest and tourist potential.

Nothofagus antarctica (Forster) Oerst., Nire, is an endemic species in Chilean and Argentinean temperate subantarctic rainforests and presents the wider distribution within Southamerican Nothofagus species. Its distribution in Chile extends from the Andinean foothills in the Maule region to the southern limit in the Cabo de Hornos in the Magallanes region. The Forest Subtype Ñire covers some 500 thousand hectares on the Forest Type Lenga (Nothofagus pumilio). In Argentina grows through wide areas on the Andes ranges up to the southern part on the Beagle channel shore and its cover is estimated at 750 thousand hectares.

Nire is a secondary species in terms of Wood production, but has an important presence in the Chilean and Argentinean Patagonia in forests distributed up to the altitudinal limit, accompanying Lenga or as pure Ñire forest in the higher zones. Main uses for Nire are wood for minor applications and firewood, however its natural forests are of great environmental and landscape importance and also for agroforestry systems combined with cattle or sheep breading activities.

Since the Aysén region has wide soil areas without forest cover or with degraded native forests cover, because of forest fires and deforestation for livestock breeding in the past, Nire is now an important species for afforestation or native ecosystems restoration.

The species has a great plasticity and can adapt to a wide site conditions variety, but its seeds have a low capacity to germinate and this is a limitation to seedling production in nursery. This problem has motivated the Chilean Forestry Institute to start a research line on sexual and asexual deployment techniques for Ñire.

The present paper shows the first results with propagation techniques and so far results are not good. Different treatments were tested to improve seeds germination level in laboratory and to stimulate cuttings root formation under glasshouse, however the first results shows that maximum germination obtained by using seeds frost stratification is $28 \%$ and cuttings root formation reached $23 \%$ by using previous immersion in indol butyric acid.

Key words: Ñire, Nothofagus antarctica, seeds pretreatmant, cuttings root formation. 


\section{INTRODUCCIÓN}

La Región de Aysén se encuentra en el sur austral de Chile, entre los paralelos $44^{\circ}$ y $49^{\circ}$ LS, aproximadamente, y se extiende desde el océano Pacífico hasta la frontera con Argentina. Es la tercera región más extensa del país (10,9 millones de hectáreas, $14,5 \%$ de la superficie continental nacional) después de Antofagasta y Magallanes, y es la que dispone de la mayor cubierta de bosques nativos (4,4 millones de hectáreas, que representan el $40,4 \%$ de la superficie regional y $32,6 \%$ de la superficie de bosques nativos del país). La región además reúne el 35,5\% de los recursos hídricos del país.

Las características indicadas se traducen en una amplia variedad de ecosistemas y una rica biodiversidad acuática y terrestre, confiriendo a la región grandes potenciales en ámbitos como el forestal y el turístico, entre otros recursos y atractivos.

Los recursos forestales de la región son a 2012 los indicados en el Cuadro $N^{\circ} 1$.

\section{Cuadro $\mathrm{N}^{\circ} 1$ \\ CUBIERTA FORESTAL REGIÓN DE AYSÉN}

\begin{tabular}{|c|c|}
\hline Cubierta Forestal & $\begin{array}{l}\text { Superficie } \\
\text { (ha) }\end{array}$ \\
\hline \multicolumn{2}{|l|}{ Bosque Nativo } \\
\hline Tipo Forestal Ciprés de Las Guaitecas & 159.334 \\
\hline Tipo Forestal Lenga & 1.400 .376 \\
\hline Tipo Forestal Coihue de Magallanes & 939.166 \\
\hline Tipo Forestal Siempreverde & 1.899 .869 \\
\hline Subtotal & 4.398.745 \\
\hline \multicolumn{2}{|l|}{ Plantaciones Forestales } \\
\hline Eucalyptus nitens & 5 \\
\hline Pinus ponderosa & 24.404 \\
\hline Pseudotsuga menziesii & 4.334 \\
\hline Otras Especies & 14.057 \\
\hline Subtotal & 42.800 \\
\hline Total & 4.441 .545 \\
\hline
\end{tabular}

(Fuente: INFOR, 2014)

En el pasado y hasta mediados del siglo XX la región sufrió grandes pérdidas de bosques nativos debidas a incendios forestales y a desmontes de terrenos para uso agrícola y ganadero, lo que ha dejado extensas superficies de suelos desarbolados y bajo fuertes procesos erosivos que deben ser forestados. Posteriormente, el sector forestal regional ha estado sometido a diferentes cambios, desde ser un importante productor de madera aserrada de especies nativas, principalmente lenga, rubro que constituyó la principal actividad productiva forestal en la región, hasta la situación actual en que la leña ha pasado a ser el producto con mayor aporte al PIB del sector en la región, dada su alta demanda por la población. Se estima que el consumo de leña de las ciudades de Coyhaique y Puerto Aysén, en conjunto, es de $373.594 \mathrm{~m}^{3}$, equivalentes a 277.219 $\mathrm{t}$, un $75 \%$ del consumo total regional.

La producción de plantas para forestación y reforestación en la región se concentra en especies exóticas del género Pinus y solo muy marginalmente en especies nativas para suplir las 
demandas internas de algunos proyectos de forestación y reforestación, sin embargo los resultados no han sido muy alentadores, dada la calidad de las plantas producidas y la pobre oferta de semillas, tanto en cantidad como en calidad. Esta situación ha derivado en prácticas no sustentables de recolección de plantas directamente de la regeneración natural en los bosques, material que resulta poco uniforme y de calidad inadecuada para estos proyectos.

La producción de plantas de calidad se ha tornado un desafío importante del sector forestal regional, por lo que proveer de información técnica adecuada provocaría un impacto positivo en el éxito de proyectos de forestación, reforestación, recuperación ecológica y restauración con especies nativas. Esta situación ha motivado a INFOR a desarrollar líneas de investigación al respecto y el presente trabajo entrega información sobre los avances logrados con ñire (Nothofagus antactica), en producción sexuada y asexuada de plantas.

\section{DESCRIPCIÓN DE LA ESPECIE}

\section{Descripción General}

Nothofagus antarctica (Forster) Oerst. Corresponde a la familia Fagaceae, se la conoce como ñirre o ñire y es un árbol nativo de Chile y Argentina. Es una especie monoica que se presenta como árbol pequeño o arbusto achaparrado, aunque generalmente alcanza los $10 \mathrm{~m}$ de altura. Sin embargo, en condiciones óptimas de sitio puede alcanzar los $15 \mathrm{~m}$ y fustes de $60 \mathrm{~cm}$ de diámetro (Rodríguez et al., 1983; Donoso, 1974), incluso se han encontrado individuos de $24 \mathrm{~m}$ de altura en la comuna de Puerto Ibáñez.

Diferentes morfotipos han sido identificados para la especie en Chile y diferentes ecotipos han sido sugeridos dentro del parque Nacional Nahuel Huapi en el noroeste de la Patagonia Argentina, en donde ñire crece en cuatro tipos de hábitats, presentando distintas características arquitectónicas para su crecimiento individual en contraste con cada entorno físico (Steinke et al. 2008).

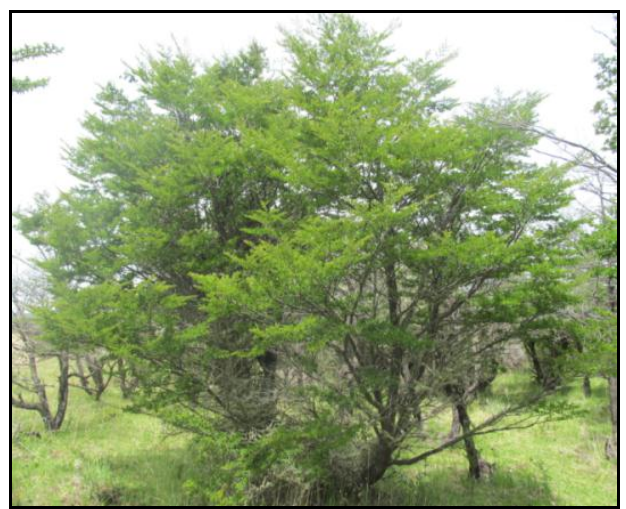

(Foto: Jaime Salinas)

Figura $\mathrm{N}^{\circ} 1$

ASPECTO GENERAL DE ÑIRE

La especie exhibe polimorfismo intraespecífico, el cual se ha asociado a una adaptación a los distintos biotopos, modificando su cuerpo vegetativo y adoptando distintas formas de vida (Donoso, 2006). 
Según Romero (1986) estos ecotipos podrían ser resultado de presiones de selección relativamente recientes tendientes a la especiación. Observaciones realizadas en terreno sugieren que en sitios donde ñire coexiste simpátricamente con lenga (Nothofagus pumilio) habrían individuos con morfología foliar intermedia entre ambas especies, que serían posibles híbridos en áreas de traslapo de los rangos de distribución de ambas especies (Donoso, 2006).

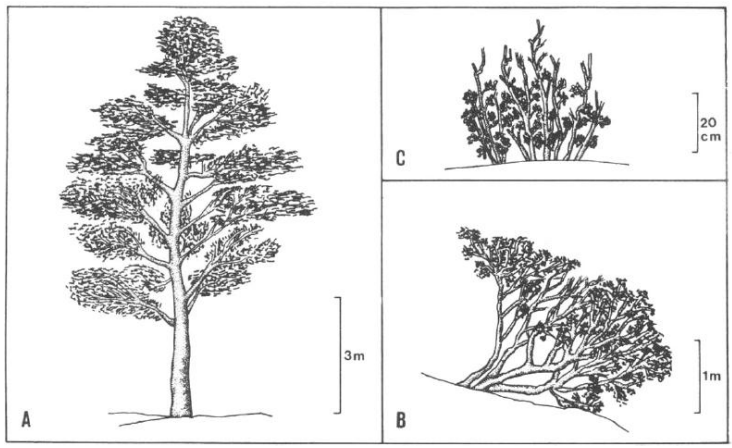

(Fuente: Ramírez et al., 1985).

$\mathrm{A}=$ Arborescente. $\mathrm{B}=$ Arbustivo achaparrado.

$\mathrm{C}=$ Camefítico de turbera.

\section{Figura $\mathrm{N}^{\circ} 2$ \\ REPRESENTACIÓN ESQUEMÁTICA DE LOS TIPOS MORFOLÓGICOS DESCRITOS PARA ÑIRE EN CHILE}

Su corteza es de color gris, rugosa, áspera y muy agrietada longitudinalmente, en forma irregular. Presenta hojas pequeñas $(0,6$ a $3,5 \mathrm{~cm}$ de largo), aovado-redondeadas a oblongas, con base acorazonada; bordes finamente dentados, lobulados y ondulados. Muestra flores femeninas y masculinas y frutos formados por 3 pequeñas nueces, de las cuales 2 son triangulares, las que rodean a una plana que se sitúa en el centro (Hoffmann, 1997).

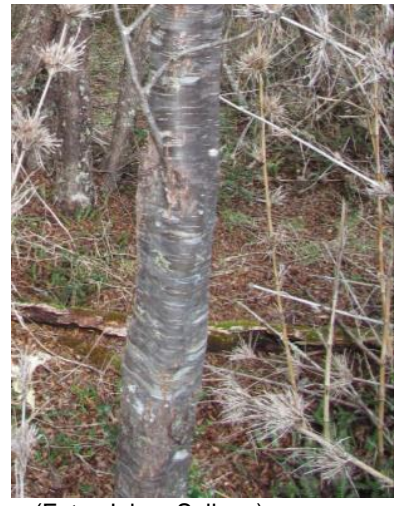

(Foto: Jaime Salinas)

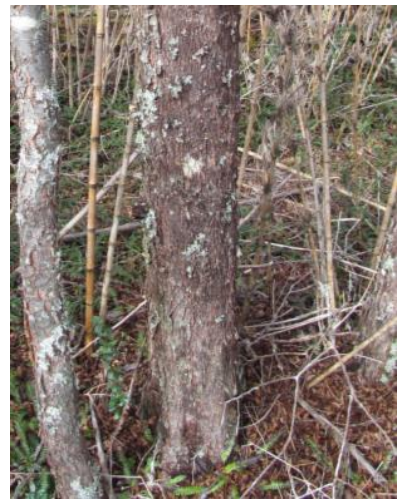

Figura $\mathrm{N}^{\circ} 3$

CORTEZA DE ÑIRE. ETAPA JUVENIL INICIAL (Izq.) Y ETAPA JUVENIL AVANZADA (Der.) 


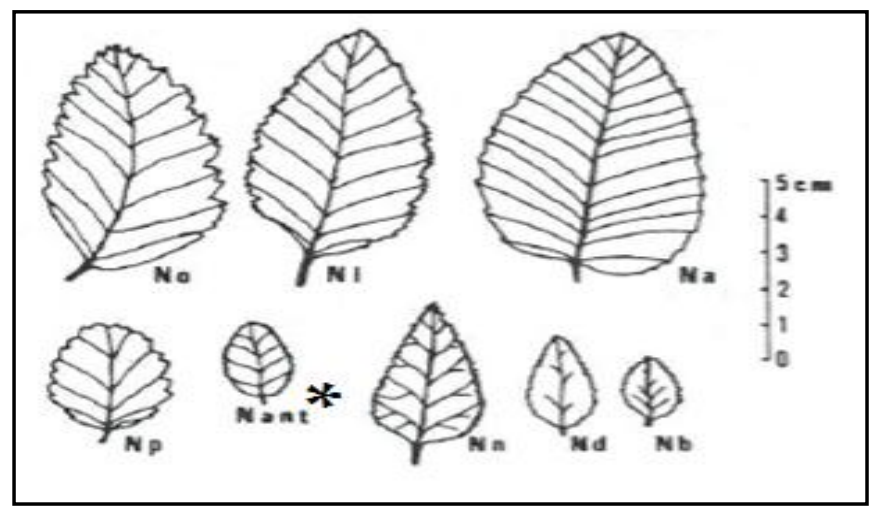

(Fuente: Adaptado de Ramírez, 1987)

No = Nothofagus obliqua, $\quad \mathrm{NI}=$ Nothofagus leoni,

$\mathrm{Na}=$ Nothofagus alessandri, $\mathrm{Np}=$ Nothofagus pumilio

Nant $=$ Nothofagus antarctica, $\mathrm{Nn}=$ Nothofagus nítida,

$\mathrm{Nd}=$ Nothofagus dombeyi,$\quad \mathrm{Nb}=$ Nothofagus betuloides

Figura $\mathrm{N}^{\circ} 4$

HOJAS DE ALGUNAS DE LAS ESPECIES CHILENAS DEL GÉNERO NOTHOFAGUS

\section{Distribución Geográfica}

Es una especie endémica de los bosques templados lluviosos o subantárticos de Chile y Argentina (Rodríguez et al. 1983; Donoso, 2006), su distribución es muy amplia, abarcando aproximadamente $2.300 \mathrm{~km}$, desde la región del Maule, en el cerro Imposibles (35¹8' S) en la precordillera andina de la comuna de Molina, provincia de Curicó, región del Maule, hasta el límite sur de Cabo Hornos (5558' S), en la provincia Antártica Chilena, región de Magallanes (Ramírez, 1987).

Por la cordillera de la costa se la encuentra en forma fragmentada entre los 35 y $36^{\circ}$ LS, la distribución es discontinua, encontrándose una pequeña población de la especie en el sur oeste de la región del Maule, provincia de Cauquenes, en el lugar denominado Paso Mora (3549' LS). Posteriormente, la especie reaparece en las alturas de la Cordillera de Nahuelbuta, provincia de Malleco en la región de la Araucanía (entre los $37^{\circ} 40^{\prime}$ y los $38^{\circ} \mathrm{LS}$, aproximadamente), en áreas más altas y bolsones de frio como parte del Tipo Forestal Araucaria (Donoso, 2006). Más al sur se vuelve a encontrar en las partes altas de la Cordillera de la Costa (Cordillera Pelada), provincia de Valdivia $\left(40^{\circ} \mathrm{LS}\right.$ hasta $\left.43^{\circ} \mathrm{LS}\right)$, y en la Isla de Chiloé de la provincia homónima en la región de Los Lagos.

En la depresión intermedia existen algunos ejemplares de ñire en una zona de Ñadis al norte de Puerto Montt, en las provincias de Llanquihue y Osorno, región de Los Lagos (entre los $40^{\circ} 50^{\prime}$ y $\left.\operatorname{los} 41^{\circ} 25^{\prime} \mathrm{LS}\right)$.

Ñire presenta el rango de distribución más amplio de los Nothofagus sudamericanos. Está presente en 39 unidades del Sistema Nacional de Áreas Silvestres Protegidas por el Estado (SNASPE) con una cobertura mínima de 77.915 ha (Ormazabal y Benoit, 1987). Donoso (2006) menciona que en Chile existen 501.372 ha del Subtipo Forestal Nire, dentro del Tipo Forestal Lenga. Dentro de esta gran área, ñire se presenta en forma discontinua, colonizando todo tipo de biótopos extremos que están vedados al resto de las especies del género (Ramírez et al., 1985). 


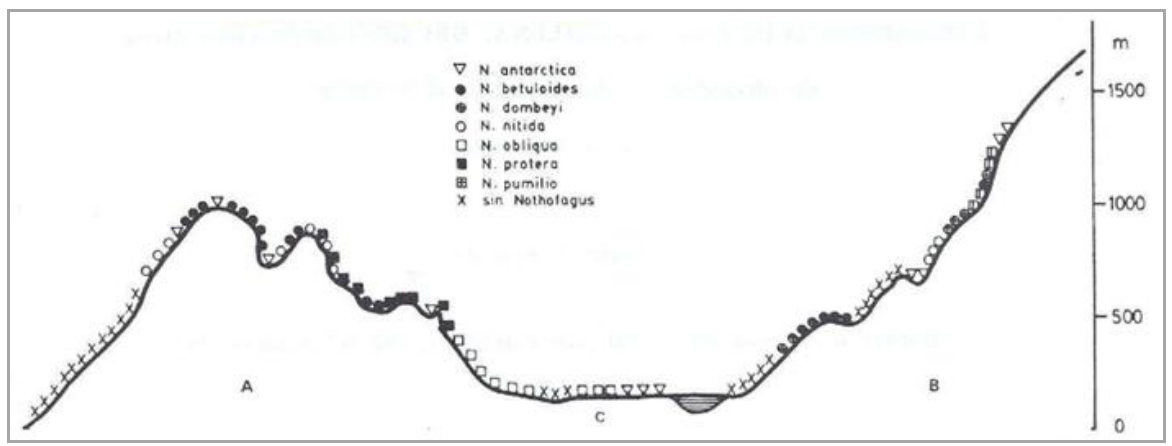

(Fuente: Alberdi, 1987).

Perfil de la Cordillera de la Costa (A), Valle Central (C) y Los Andes (B)

Perfil costero corresponde a Cordillera de Pelada (Valdivia) y Andino a Parque Nacional Puyehue (Osorno)

Figura $N^{\circ} 5$

ESQUEMA DE LA DISTRIBUCIÓN ALTITUDINAL DE ESPECIES DEL GÉNERO NOTHOFAGUS

En la Región de Aysén la superficie cubierta por bosques de ñire es de 220.000 ha aproximadamente, es posible encontrarlo creciendo en sitios con suelos profundos y bien drenados donde adquiere características arbóreas optimas, en condiciones de humedad estacional y permanente (mallines) y en el límite altitudinal de la vegetación, adoptando una fisonomía de bosque achaparrado compartiendo hábitat con los Krummholz de lenga.

En Argentina crece en una amplia extensión en las cumbres de la cordillera de Los Andes, hasta el extremo sur en las riberas del canal Beagle, y se extiende por debajo de los 600 msnm, introduciéndose hacia la estepa junto a araucaria (Araucaria araucana) en el norte y a ciprés de la cordillera (Austrocedrus chilensis) más hacia el sur (Vidal y Premoli, 2004). En la Patagonia Argentina existen cerca de 99.000 ha de bosques de ñire de tipo arbóreo en la provincia de Santa Cruz y 181.370 ha en Tierra del Fuego, distribuidas en un amplio rango de condiciones ambientales (Bahamonde et al., 2011) con una cobertura de $7.500 \mathrm{~km}^{2}$.

\section{Condiciones Climáticas}

La flora de los bosques templados del sur de Sudamérica tiene un origen y desarrollo ligado a los principales eventos geológicos y climáticos que ocurrieron durante la prehistoria. Las características geográficas del extremo austral de Sudamérica se caracterizan por una elevada heterogeneidad en el ambiente físico, por la presencia de la cordillera de Los Andes y del Océano Pacífico, que determinan marcados gradientes climáticos que afectan los bosques subantárticos (Donoso, 2006).

En su distribución más austral, en Tierra del Fuego, el clima está relacionado con las características de la circulación de la atmósfera y las corrientes oceánicas a las latitudes involucradas, la influencia de la masa de hielo antártico, la naturaleza insular del territorio y la localización de la cordillera de los Andes. En la Patagonia, la cordillera es una barrera para los vientos occidentales semipermanentes emitidos por el anticiclón del Pacífico Sur, que son obligados a ascender, enfriándose y precipitando su humedad mayormente sobre los flancos occidentales de Los Andes y provocando fuertes gradientes descendentes de precipitaciones hacia la Patagonia extra andina (Frangi et al., 2004; Bahamonde et al., 2011).

Ñire puede desarrollarse en variados ambientes con diferencias en las condiciones climáticas. En sitios óptimos, con suficiente humedad, bien drenados, donde los suelos son fértiles y las variaciones de temperaturas anuales y diarias son moderadas, esta especie crece sin 
mayores problemas, adquiriendo hábito arbóreo. No obstante, es posible que ñire crezca en suelos con variaciones hídricas amplias a lo largo del año, pobres en fertilidad y pedregosos, en zonas alto andinas y en el ecotono bosque-estepa, donde presenta un crecimiento de menor altura, y en sitios de extrema humedad y mal drenaje adopta progresivamente carácter de planta achaparrada 0 Krummholz (Ramírez et al. 1985; Veblen et al. 1996; Donoso 2006).

En un estudio realizado por Gargaglione et al. (2013) se analizaron las características climáticas y edáficas de las tres calidades de sitio (III, IV y V) para ñire en el SO de la provincia de Santa Cruz, Argentina, y estas se caracterizan por temperaturas medias anuales que oscilan entre $5,4^{\circ}$ y $5,9^{\circ} \mathrm{C}$, y precipitaciones desde los 335 a los $563 \mathrm{~mm} / \mathrm{año}$.

En el límite de su distribución norte, ñire se desarrolla sobre climas más bien mediterráneos, en sectores con humedad permanente sin extremos de temperatura en quebradas y cerca de cursos de agua (San Martin et al., 1988; Donoso, 2006). En la zona centro sur de Chile se refleja su gran plasticidad al ubicarse en diferentes gradientes altitudinales, soportando heladas en invierno de hasta $-22^{\circ} \mathrm{C}$ (Alberdi, 1995). Ya en la zona sur se encuentra en la depresión central en los ñadis, bajo condiciones de mucha humedad del suelo en invierno y de alta sequedad en verano. Hacia el sur se mantiene en las islas y el continente bajo condiciones de clima oceánico templadohúmedo, y continúa hacia el sur con condiciones siempre húmedas pero más frías y ventosas (Donoso, 2006).

En la cordillera de Los Andes crece en los límites altitudinales de la vegetación arbórea, en bolsones de frio, en sustratos pobres en fertilidad y pedregosos, muy secos o húmedos dependiendo de la pendiente. En la depresión central se desarrolla sobre terrenos planos y suelos conocidos como Nadis, suelos de cenizas volcánicas superficiales que presentan a poca profundidad un hardpan de fierrillo que determina las variaciones hídricas del sitio.

En la zona austral, en Magallanes y Tierra del Fuego, se encuentra en zonas ecotonales entre el bosque y la estepa, en morrenas de los sectores de glaciaciones y también en los límites de la vegetación arbórea, todas condiciones de drenaje restringido, bajas temperaturas y fuertes vientos (Premoli, 1991; Vidal y Premoli, 2004).

\section{Diseminación, Cosecha y Germinación de Semillas}

La regeneración del bosque es un proceso dinámico que incluye distintas etapas, desde la floración hasta la instalación y supervivencia de plantas, y cuyo éxito final dependerá de distintos factores bióticos y abióticos que incidirán en cada etapa del proceso (Bahamonde et al., 2013).

La floración de la especie comienza entre octubre y noviembre, y la maduración de los frutos se produce en abril (Donoso y Cabello, 1978; Donoso, 2006). Sin embargo, es probable que las fechas de floración y fructificación varíen en las diferentes latitudes y en diferentes biotopos.

Las semillas de ñire son pequeñas y con alas reducidas, el tamaño del fruto y el escaso peso facilitan que el viento las transporte con facilidad, también es posible que sean diseminadas por el agua y la gravedad (Donoso, 2006). Las semillas de los individuos pertenecientes a los distintos morfotipos arbóreos resultan más pesadas y con mayor capacidad germinativa que las semillas de los individuos que presentan crecimiento achaparrado (Premoli, 1991). Las condiciones ambientales en donde crecen los individuos achaparrados estarían afectando directamente la vitalidad y capacidad reproductiva de estos.

Bahamonde et al. (2011) cuantificaron la producción de semillas anuales y su viabilidad germinativa en rodales puros en tres calidades de sitio diferentes en la Patagonia Sur de Argentina, observando que la germinación varió entre sitios independientemente de la producción de semillas (que fluctuó desde 2 a 52 millones), no superando el $12 \%$ en promedio para todos los años evaluados. 


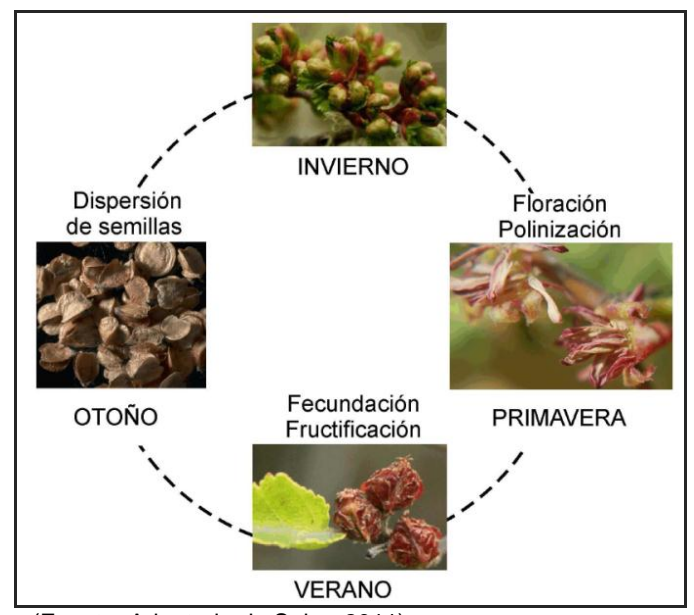

(Fuente: Adaptado de Soler, 2011)

Figura $N^{\circ} 6$ CICLO DE VIDA DE ÑIRE

Las especies de Nothofagus poseen semillas que son principalmente dispersadas por el viento (anemócoras), sus nueces son dehiscentes de modo que las semillas son liberadas del fruto (aquenio) al madurar, son aladas y pueden ser transportadas por el viento (Donoso, 2006). Generalmente, los Nothofagus presentan sus frutos en la parte superior de las copas lo que dificulta su recolección y esta habitualmente se efectúa trepando para cosechar directamente de árboles en pie. Otra forma es cosechar de árboles volteados aprovechando alguna intervención silvícola. Independientemente del método utilizado para obtener las semillas, es de gran importancia la adecuada identificación de cada lote, registrando información de ubicación geográfica, altitud, edad estimada del árbol y fecha de recolección entre otros antecedentes.

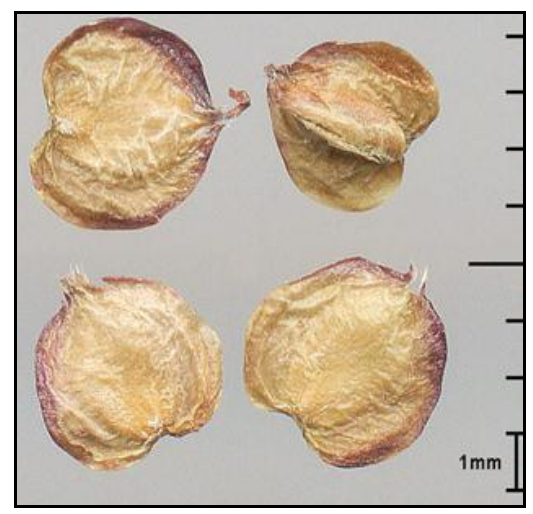

Figura $\mathrm{N}^{\circ} 7$

TAMAÑO Y FORMA DE LAS SEMILLAS DE ÑIRE 


\section{METODOLOGÍA}

\section{Área de Recolección del Material de Propagación}

El estudio se realizó en la comuna de Coyhaique, Región de Aysén.

Se seleccionaron dos predios con formaciones de ñire, ubicados en el sector de Balmaceda (Figura $N^{\circ} 8$ ).

Esta zona se caracteriza por presentar un clima de estepa fría de vertiente oriental de Los Andes patagónicos o transandinos y está protegida por el cordón montañoso de la cordillera, lo que se traduce en una disminución notable de las precipitaciones en comparación con el sector de archipiélagos (clima oceánico) que se encuentran en la misma latitud. (Balmaceda).

En la vertiente oriental los valores de las precipitaciones bajan hasta $621 \mathrm{~mm}$ anuales

\section{- Material Vegetativo}

Se recolectaron dos procedencias de estacas durante junio del año 2014, estas fueron extraídas de árboles con características fenotípicas superiores en comparación a sus pares.

Se eligieron los últimos brotes de cada árbol y luego fueron depositados en contenedores plásticos y cubiertos con papel periódico humedecido, para ser transportados al vivero.

El Cuadro $\mathrm{N}^{\circ} 2$ indica los predios seleccionados para la recolección de material vegetativo (estacas) para reproducción asexual.

\section{Cuadro $\mathrm{N}^{\circ} 2$}

PREDIOS DE RECOLECCIÓN DE MATERIAL VEGETATIVO

\begin{tabular}{|c|c|c|c|c|c|c|}
\hline Sitio & Predio & Latitud & $\begin{array}{c}\text { Altitud } \\
(\mathbf{m s n m})\end{array}$ & $\begin{array}{c}\text { Características } \\
\text { Individuos }\end{array}$ & Ubicación & $\begin{array}{c}\text { Condición } \\
\text { Hídrica }\end{array}$ \\
\hline \multicolumn{7}{|l|}{} \\
\hline I & Vista Hermosa & $45^{\circ} 52^{\prime}$ & 536 & Arbóreo $(8 \mathrm{~m})$ & Balmaceda & Mallín \\
& Los Mallines & $45^{\circ} 50^{\prime}$ & 564 & Arbóreo $(8 \mathrm{~m})^{*}$ & Balmaceda & Seco \\
\hline
\end{tabular}

${ }^{*}$ Altura media del dosel

La primera procedencia corresponde a un sitio de ñirrantal en un sector húmedo relacionado a un mallín en la zona cercana a Balmaceda. La segunda corresponde a un bosque de ñire en un sitio sin influencia de napa freática (sitio más seco) ubicado en la zona de Galera Chico.

El ensayo de reproducción vegetativa se montó en el vivero del Instituto Forestal sede Patagonia, en la ciudad de Coyhaique. El ensayo se ubicó al interior de un invernadero, sobre una cama caliente que contiene arena como sustrato. 


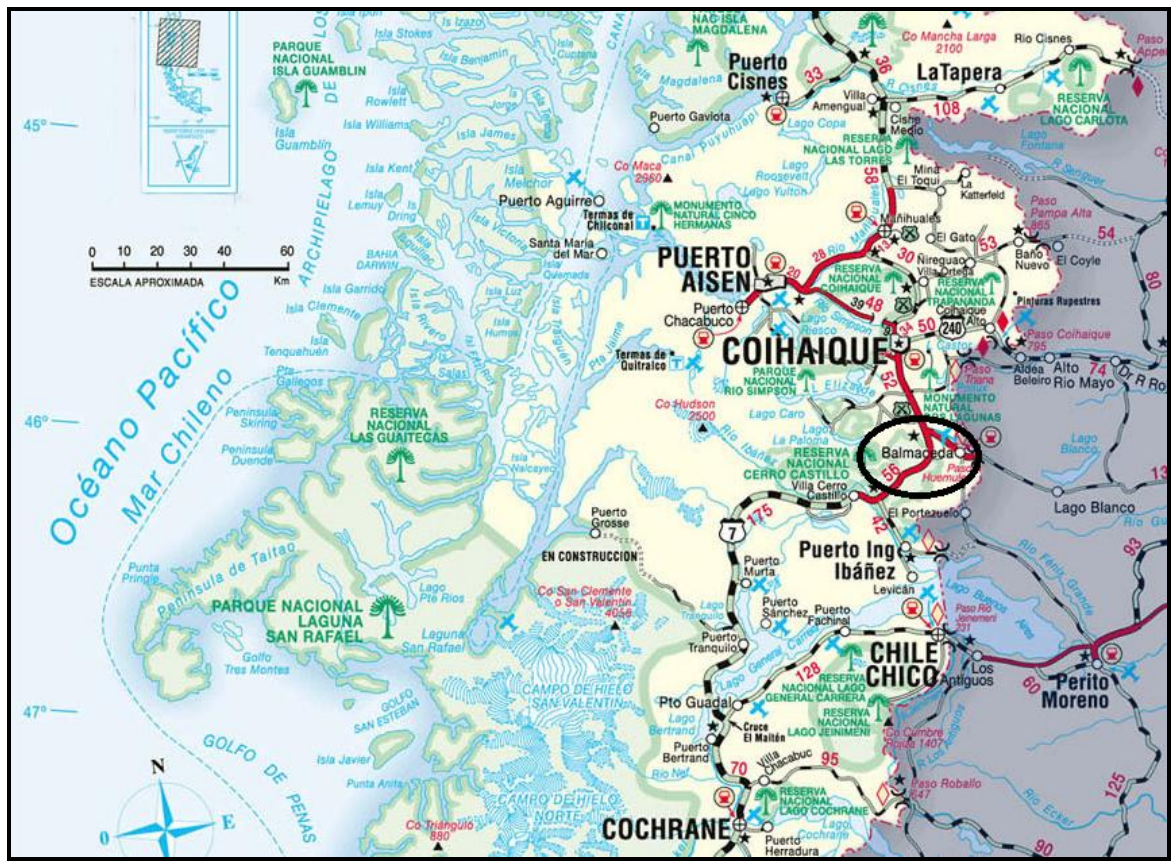

En círculo negro la ubicación de los predios Los Mallines y Vista Hermosa en la comuna de Coyhaique, Región de Aysén.

Figura $N^{\circ} 8$

UBICACIÓN GEOGRÁFICA LUGAR DE COLECTA DE SEMILLAS Y ESTACAS DE ÑIRE

\section{- Semillas}

La recolección de semillas en Aysén comienza a fines del verano y parte del otoño, dependiendo de estado de madurez y las condiciones climáticas que imperen en la zona (Salinas et al., 2013).

Para extraer las semillas de ñire se cortaron ramas durante el mes de marzo del año 2014 del sector Vista Hermosa, comuna de Coyhaique (45 $48^{\prime}$ LS - $71^{\circ} 54^{\prime}$ LO). Las semillas fueron almacenadas en depósitos plásticos y llevadas al vivero para su extracción y limpieza.

El ensayo de reproducción sexual se llevó a cabo en dependencias del Instituto Forestal sede Bío Bío en la ciudad de Concepción. Las semillas ingresaron al laboratorio durante el mes de julio para su posterior análisis y proceso.

\section{- Antecedentes Meteorológicos}

La caracterización de las principales variables climáticas del área de recolección de material de propagación se efectuó sobre la base de la información recopilada en una estación meteorológica permanente ubicada en el sector Vista Hermosa, correspondiente a La Red Agrometeorológica de INIA (AGROMET, 2014). En la Figura $\mathrm{N}^{\circ} 9$ se indican las temperaturas medias mensuales y en la Figura $\mathrm{N}^{\circ} 10$ las precipitaciones mensuales, ambos antecedentes para el año 2014. 


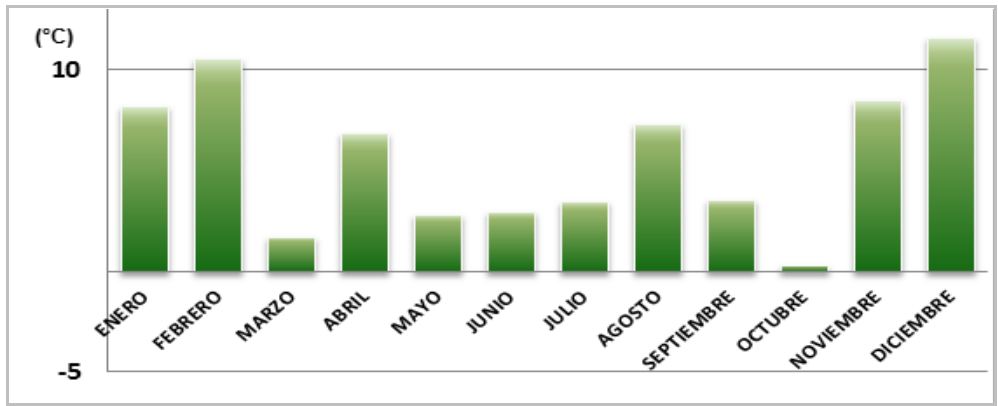

(Fuente: http://agromet.inia.cl).

Figura $\mathbf{N}^{\circ} 9$

TEMPERATURA MEDIA AÑO 2014 SECTOR VISTA HERMOSA COMUNA DE COYHAIQUE

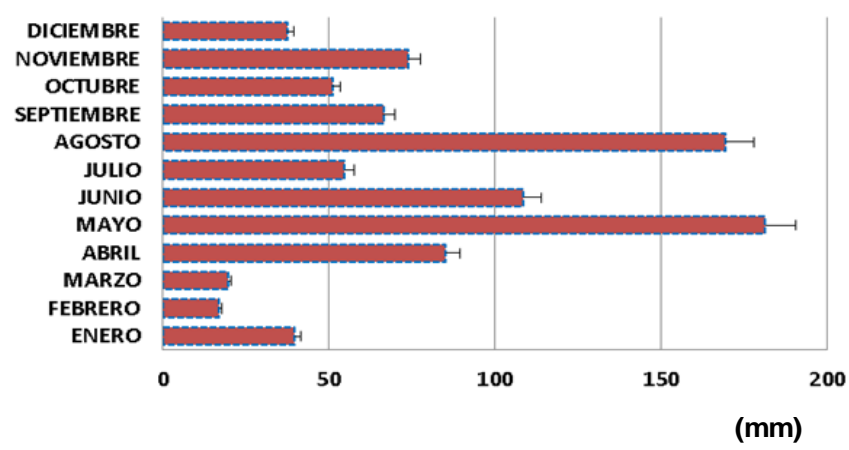

(Fuente: http://agromet.inia.cl)

Figura $N^{\circ} 10$

PRECIPITACION MENSUAL AÑO 2014 SECTOR VISTA HERMOSA COMUNA DE COYHAIQUE

Las temperaturas medias mensuales tienden a ser inferiores a $10^{\circ} \mathrm{C}$ durante gran parte del año, con mínimos en los meses de marzo y octubre y máximos en los meses de noviembre a febrero. Las preciptaciones en tanto muestran niveles máximos en los meses de mayo y agosto, por sobre los $150 \mathrm{~mm} / \mathrm{mes}$, y mínimos en el período enero a marzo, bajo los $50 \mathrm{~mm} / \mathrm{mes}$.

En general, las precipitaciones en zonas de transición esteparia son bajas, aun así, en situaciones donde ñire se desarrolla en mallines, con presencia de un hardpan de fierrillo en el suelo, se generan condiciones restringidas de drenaje, lo que sumando a las bajas temperaturas y la fuerza de los vientos, tornan a estos sectores en sitios poco adecuados para el desarrollo de masas boscosas. No obstante, ñire es una especie con adaptación a este tipo de condiciones ambientales.

\section{- Antecedentes de Suelos}

La informacipon general de suelos para el área de recolección de material de 
propagación (IREN, 1979) indica que estos corresponden a la Asociación de Suelos Balmaceda, caracterizados por texturas finas (muy arcillosas, arcillo limosas, arcillo arenosas), baja permeabilidad y alta escorrentía, y un alto grado de erosión.

IREN (1979) indica que la asociación Balmaceda abarca una superficie de 3.250 ha, desde el norte del aeropuerto internacional hasta el río Simpson y por el este hasta el río Oscuro. Su posición fisiográfica corresponde a un plano de inundación, con relieve plano o casi plano y con ligeros a fuertes micro relieves producidos por la erosión eólica.

El drenaje es pobre a muy pobre, encontrandose áreas de drenaje muy restringido. Los suelos se han desarrollado a partir de sedimentos finos de origen fluviolacustres y lacustres que han formados perfiles estratificados.

Son suelos profundos, con moderada agregación en superficie y escaso desarrollo del perfil. Sus texturas se van haciendo finas en profundidad y el color, dominante gris, evidencia los problemas de drenaje del área.

Los suelos de esta asociación se han clasificado mayoritariamente la mayor parte en Clase de Capacidad de Uso VIw, no obstante su condición de humedad se encuentra fuertemente atenuada por los vientos.

\section{Ensayo de Reproducción Vegetativa}

Como se indicó, el ensayo de reproducción vegetativa se instaló en el vivero del Instituto Forestal en la ciudad de Coyhaique, al interior de un invernadero provisto de cama caliente que contiene arena como sustrato.

\section{- $\quad$ Registro de Temperaturas}

Con el fin de determinar el comportamiento de la temperatura ambiental en el invernadero durante el ensayo de enraizamiento, se registraron diariamente las temperaturas extremas usando un termómetro de máximas y mínimas.

Además, se registró la temperatura del sustrato, a través, de un termómetro de suelo.

La temperatura de las camas calientes se evalúo y controló a través de dos termómetros digitales con base metálica, la evaluación se realizó dos veces al día, controlando el termostato para que la temperatura se mantuviera entre $18^{\circ}$ y $25^{\circ} \mathrm{C}$.

\section{- Preparación de Estacas}

Para la elaboración de las estacas se procedió a cortar las ramas extraídas de los árboles en segmentos de $15 \mathrm{~cm}$ de longitud, mediante el uso de una tijera de poda manual.

Se eliminaron las hojas de la base de cada estaca para dejar 1 o 2 hojas de la mitad superior evitando de esta forma la excesiva perdida de humedad a través de la transpiración (Figura $\mathrm{N}^{\circ} 11 \mathrm{~A}$ ).

Una vez elaboradas, las estacas se depositaron en una bandeja plástica con cubierta de papel humedecido.

El corte superior de la estaca se hizo recto, para evitar confusión en la instalación de la misma, mientras que el corte basal se realizó en bisel (Figura $\mathrm{N}^{\circ} 11 \mathrm{~B}$ ). 


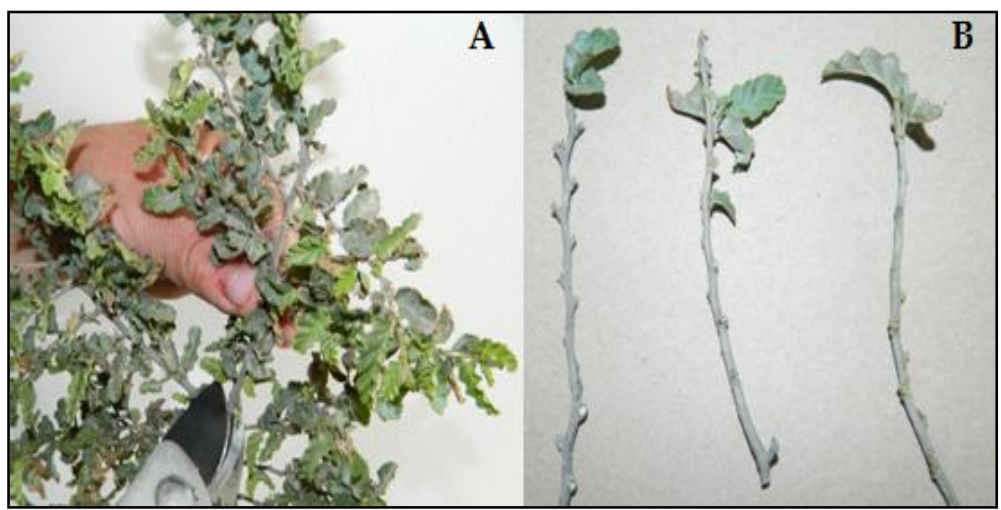

Figura $\mathrm{N}^{\circ} 11$

ELABORACIÓN DE ESTACAS

\section{- $\quad$ Tratamientos}

Siete tratamientos fueron aplicados para evaluar la capacidad de enraizamiento de las estacas. Cinco de ellos corresponden a distintas concentraciones de ácido Indolbutírico (AIB) en solución líquida, otro a una formulación de AIB en polvo y el último a un testigo sin AIB (Cuadro $N^{\circ}$ 3).

Cada tratamiento constó de tres repeticiones de 20 estacas cada una, las que totalizan 60 unidades por tratamiento. Se registró la aparición de callos y raíces en una submuestra aleatoria de cinco estacas por repetición (total 15 estacas por tratamiento). Este registro se realizó a los 15, $30,45,60$ y 90 días posteriores al establecimiento del ensayo.

La aplicación de los distintos tratamientos consistió en la inmersión de la base de las estacas durante cinco segundos en recipientes con la solución o mezcla de AIB correspondiente. Posteriormente, las estacas fueron plantadas en las camas calientes del invernadero, en filas paralelas de 20 estacas cada una, distanciadas $5 \mathrm{~cm}$ una de otra y enterradas a aproximadamente $3 \mathrm{~cm}$ de profundidad.

Cuadro $\mathrm{N}^{\circ} 3$

TRATAMIENTOS PARA EL ARRAIGAMIENTO DE ESTACAS

\begin{tabular}{|c|c|c|}
\hline Tratamiento & $\begin{array}{c}\text { Concentración } \\
\text { AlB } \\
(\mathbf{p p m})\end{array}$ & $\begin{array}{c}\text { Estacas } \\
\text { Evaluadas } \\
\left(\mathbf{N}^{\circ}\right)\end{array}$ \\
\hline T1 & 0 & 60 \\
T2 & $3.000^{(*)}$ & 60 \\
T3 & 100 & 60 \\
T4 & 200 & 60 \\
T5 & 500 & 60 \\
T6 & 1.000 & 60 \\
T7 & 2.000 & 60 \\
\hline
\end{tabular}

(T) Formulación en polvo 
Las camas calientes no fueron tratadas con estimulantes de enraizamiento, solo se aplicó fungicida para evitar el ataque de hongos en las estacas.

El riego se aplicó por aspersión y la frecuencia de este fue de dos veces diarias por 15 minutos de duración, con ello se mantiene la humedad, temperatura y aireación óptimas para la generación de raíces adventicias.

Los riegos se realizaron en la mañana y por la tarde evitando las altas temperaturas y para así reducir su evaporación.

\section{Ensayo de Reproducción por Semillas}

\section{- $\quad$ Limpieza y Manejo de Semillas}

Las semillas obtenidas desde el sector Vista Hermosa en la comuna de Coyhaique corresponden a muestras extraídas desde una agrupación de árboles ubicados en una misma área geográfica en asociaciones o manchas boscosas.

Los frutos y semillas fueron depositadas en sacos para el traslado al vivero del Instituto Forestal en Concepción, previo a esto se limpiaron, separando hojas, tallos y restos de frutos, mediante harneros de distintos pasos y una vez limpias se ventilaron a temperatura ambiente.

Las semillas fueron colectadas en marzo de 2014, después de su limpieza se obtuvo una muestra que fue enviada al laboratorio de INFOR en Concepción para la determinación de sus parámetros físicos y de germinación. (Figura №12).

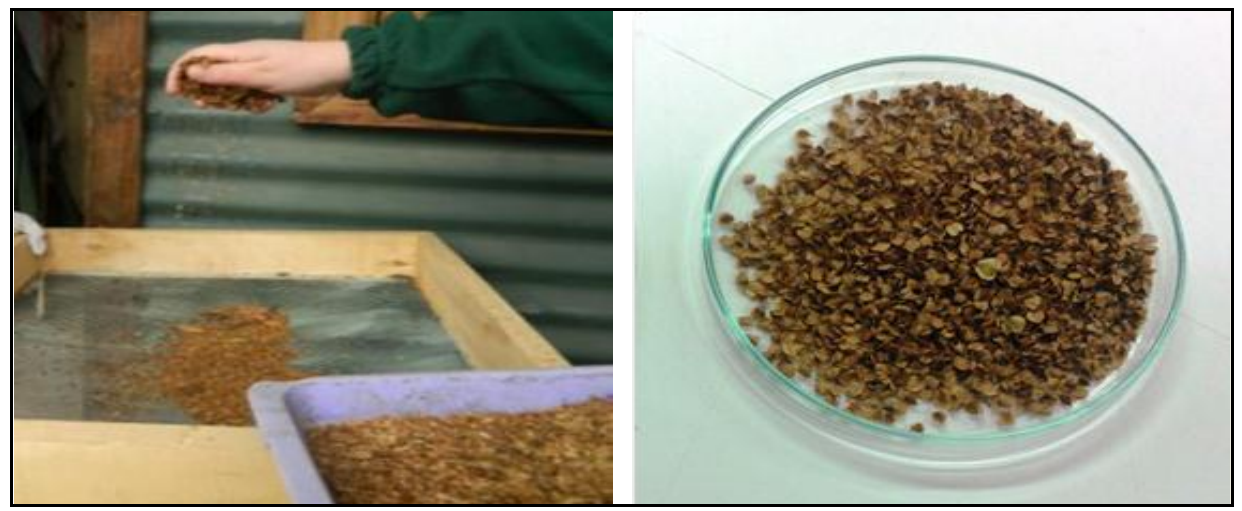

Figura $N^{\circ} 12$

LIMPIEZA Y MUESTRA DE SEMILLAS OBTENIDA

\section{- Tratamientos Pregerminativos}

Una vez en el laboratorio de INFOR en Concepción, las semillas fueron lavadas y posteriormente puestas en remojo en agua destilada a temperatura ambiente durante 7 días, cambiando el agua diariamente (Figura $\mathrm{N}^{\circ} 13$ ). 


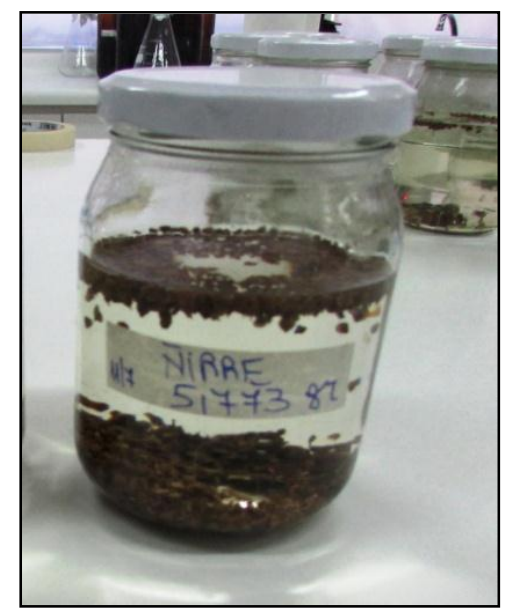

Figura $\mathrm{N}^{\circ} 13$

SEMILLAS DE ÑIRE EN REMOJO EN AGUA DESTILADA

Con posterioridad al remojo, las semillas fueron estratificadas dentro de bolsas con arena fina húmeda, previamente esterilizada, a temperatura constante de $4^{\circ} \mathrm{C}$ por 30 y 45 días.

Después de la estratificación la semillas fueron lavadas antes de instalar los ensayos (Figura $N^{\circ} 14$ ). Parte de la semilla se conservó sin estratificar como testigo frente a los tratamientos de estratificación fría (Cuadro $\mathrm{N}^{\circ} 4$ ).

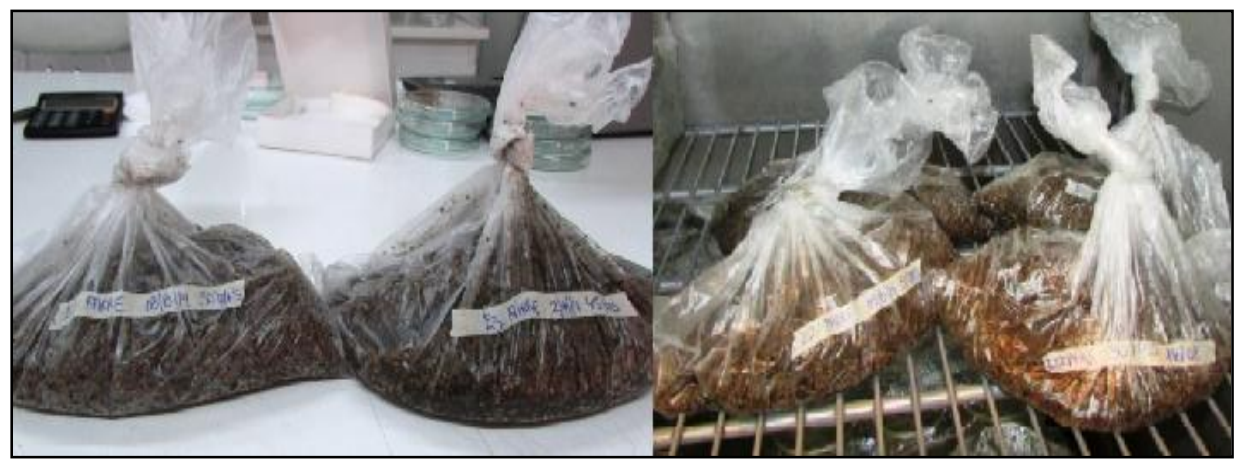

Figura $\mathrm{N}^{\circ} 14$

TRATAMIENTO PREGERMINATIVO ESTRATIFICACIÓN FRÍA 
Cuadro $\mathrm{N}^{\circ} 4$

TRATAMIENTOS PREGERMINATIVOS

\section{\begin{tabular}{l|l} 
Tratamiento & Descripción \\
\hline
\end{tabular}}

\begin{tabular}{|l|l|}
\hline E 1 & Control sin estratificación \\
\hline E 2 & Estratificación 30 días \\
\hline E 3 & Estratificación 45 días \\
\hline
\end{tabular}

\section{- Ensayos de Germinación}

Los ensayos de germinación consistieron en el establecimiento de las semillas en placas Petri con papel filtro humedecido. Cada placa fue identificada con el nombre de la especie, tipo de tratamiento, fecha de inicio del ensayo y número de repetición del lote de semilla.

Los tres tratamientos (E1, E2, E3) fueron instalados en cámara germinadora, en ausencia de luz, a temperatura constante de $23^{\circ} \mathrm{C}$, durante 30 días.

Se consideraron cuatro repeticiones de 50 semillas para cada tratamiento, en cada una de las cuales se registró diariamente el número de semillas germinadas, siendo estas la que muestran la aparición de su radícula con una longitud de al menos $1 \mathrm{~mm}$ (Figura $\mathrm{N}^{\circ} 15$ ).

Posteriormente, se graficó la germinación acumulada para cada tratamiento, expresada en porcentaje diario de germinación, y se calcularon los parámetros de periodo de energía, energía germinativa y capacidad germinativa de acuerdo a la metodología del valor máximo de Czabator (1962).

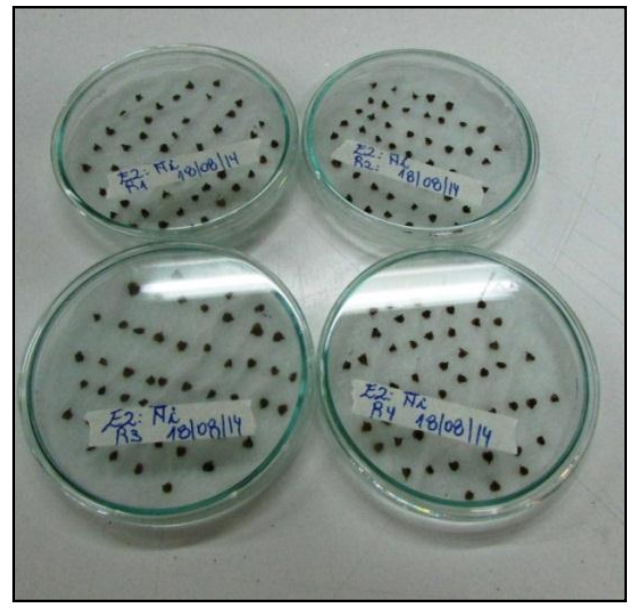

Figura $\mathrm{N}^{\circ} 15$

ENSAYOS DE GERMINACIÓN EN PLACA PETRI 


\section{- $\quad$ Análisis Físico de las Semillas}

Se determinó el número de semillas por kilo y el peso individual de la semilla.

El primero fue determinado a través de la norma ISTA (International Seed Testing Association) que exige que la muestra de trabajo corresponda a semilla pura, para determinar así el número de semillas constituidas y con capacidad germinativa potencial, eliminando semillas atrofiadas, semillas de otra especie, materia inerte u otras anormalidades, según la siguiente fórmula:

$$
\mathrm{N}^{\circ} \text { semillas } / \mathrm{kg}=\left(\mathrm{N}^{\circ} \text { semillas de la muestra / peso muestra en } \mathrm{g}\right)^{*} 1000
$$

El peso individual de la semilla en tanto se obtiene mediante extrapolación de los valores obtenidos del pesaje de las semillas (100 semillas tomadas al azar en 3 réplicas).

\section{- Energía Germinativa}

A través de la curva promedio de germinación acumulada se determinó la energía germinativa (EG), la que corresponde al porcentaje de germinación acumulado diario, obtenido al momento en que la tasa de germinación alcanza su valor máximo.

\section{- $\quad$ Periodo de Energía}

El período de energía es la cantidad de días requeridos para alcanzar la tasa máxima de germinación (Cabello et al., 2002).

\section{- Capacidad Germinativa}

La capacidad de germinación (CG) es el valor en porcentaje del total de semillas germinadas en el ensayo, que es calculado también con la curva promedio de germinación acumulada.

\section{RESULTADOS Y DISCUSIÓN}

\section{Ensayo de Reproducción Vegetativa}

\section{- $\quad$ Registro de Temperaturas}

Durante el periodo de julio a septiembre, época en que se realizó el ensayo de enraizamiento, se registró una temperatura mínima promedio de $-0,8^{\circ} \mathrm{C}$ al interior del invernadero.

Si se considera que el estudio se realizó principalmente durante la temporada de invierno, estas bajas temperaturas pudieron haberse mantenido desde la mañana y durante gran parte del día afectando de forma importante el crecimiento radicular (Figura $\mathrm{N}^{\circ} 16$ ).

La temperatura máxima promedio en tanto alcanzó los $22,1^{\circ} \mathrm{C}$, rango aceptable para el desarrollo radicular, sin embargo, se cree que esta temperatura ambiente promedio es efímera durante el día. 


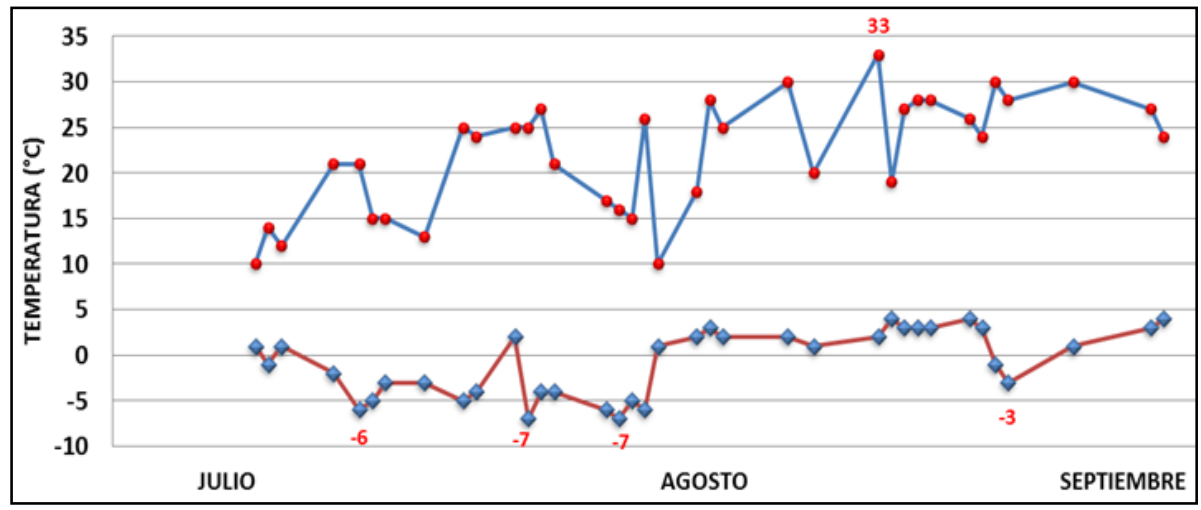

Figura $\mathbf{N}^{\circ} 16$

VARIACIÓN DE LA TEMPERATURA AMBIENTAL AL INTERIOR DEL INVERNADERO

Las temperaturas fueron medidas durante el periodo del 1 de julio hasta el 9 de septiembre. La curva azul indica la temperatura máxima, cuyo valor más alto se registró el 18 de agosto con $33^{\circ} \mathrm{C}$ y la curva en rojo indica la temperatura mínima, en donde el valor más bajo se registró el día 22 de julio con $-7^{\circ} \mathrm{C}$.

En cuanto a la temperatura del sustrato (Figura $\mathrm{N}^{\circ} 17$ ), las mediciones realizadas indican que la mínima alcanzó a $4,9^{\circ} \mathrm{C}$ (23 de julio) y la máxima a $19,4^{\circ} \mathrm{C}$ (2 de septiembre), con un promedio de $10,5^{\circ} \mathrm{C}$.

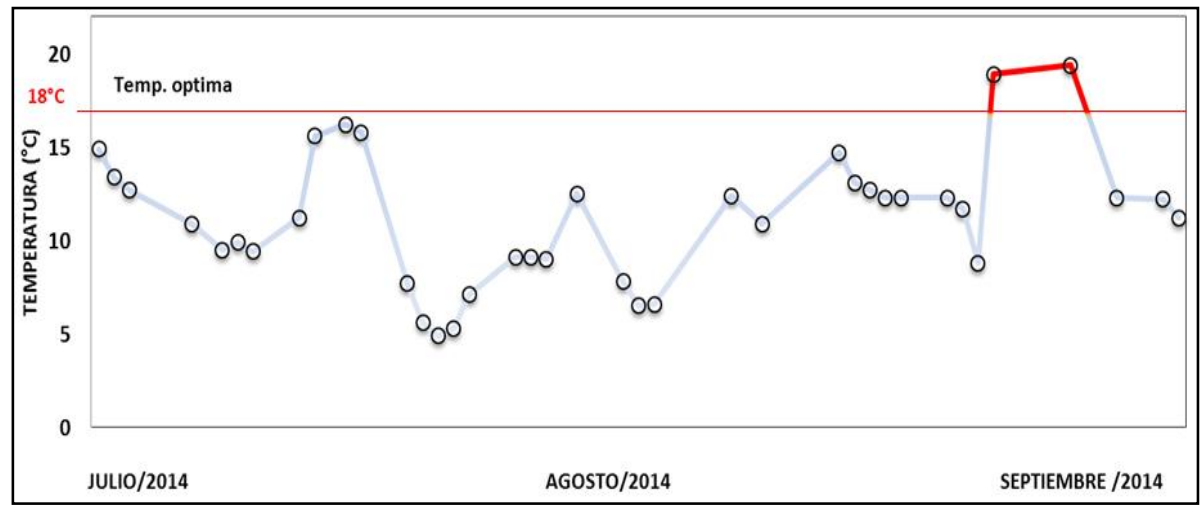

Figura $N^{\circ} 17$

VARIACIÓN DE LA TEMPERATURA DEL SUSTRATO

Desde el punto de vista fisiológico, la formación de raíces adventicias responde en mejor forma cuando las temperaturas (ambiental y del sustrato) son más altas, que las observadas en este ensayo. 
Estas mayores temperaturas generan un aumento localizado de la respiración, lo que supuestamente llevaría a la síntesis localizada de carbohidratos y posteriormente a un incremento en la cantidad citoplasmática de la célula, hecho que sería la base para una mayor división celular en el área radicular y la creación de las raíces adventicias.

Sin embargo, los factores genéticos que controlan el desarrollo de tejidos en las plantas obedecen a las distintas condiciones ambientales en donde estas se desarrollan de forma natural, por lo que la expresión génica de los tejidos radiculares se podría ver en este caso estimulada por temperaturas relativamente bajas en comparación a especies que habitan en climas más templados. Esto se demuestra en lo informado por Santelices (1993) en el enraizamiento de estacas de Drimys winteri (canelo), donde obtuvo excelentes resultados de enraizamiento con temperaturas entre los 15 y $26^{\circ} \mathrm{C}$, logrando las estacas no solo una mayor rapidez de formación de raíces sino también mayor cantidad de raíces formadas.

Como se aprecia en la Figura $\mathrm{N}^{\circ} 17$, durante la mayor parte del tiempo de evaluación se registraron temperaturas de sustrato por debajo el nivel óptimo de crecimiento radicular $\left(18^{\circ} \mathrm{C}\right)$.

\section{- $\quad$ Análisis de los Tratamientos}

Los tratamientos de diferentes concentraciones de AIB sobre las estacas fueron evaluados a los $15,30,45,60$ y 90 días posteriores al establecimiento de los ensayos.

Los resultados para el ensayo del material vegetal procedente de los predios Los Mallines y Vista Hermosa se muestran en los Cuadros $\mathrm{N}^{\circ} 5$ y $\mathrm{N}^{\circ} 6$, respectivamente.

Cuadro $\mathrm{N}^{\circ} 5$

RESULTADOS TRATAMIENTOS CON AIB PREDIO LOS MALLINES

\begin{tabular}{|l|c|c|c|c|c|c|}
\hline \multirow{3}{*}{ Tratamientos } & \multicolumn{7}{|c|}{ Evaluación } \\
\cline { 2 - 7 } & 15 & 30 & 45 & 60 & 90 & \multirow{2}{*}{ Total } \\
\cline { 2 - 6 } & \multicolumn{7}{|c|}{ (días) } \\
\hline
\end{tabular}

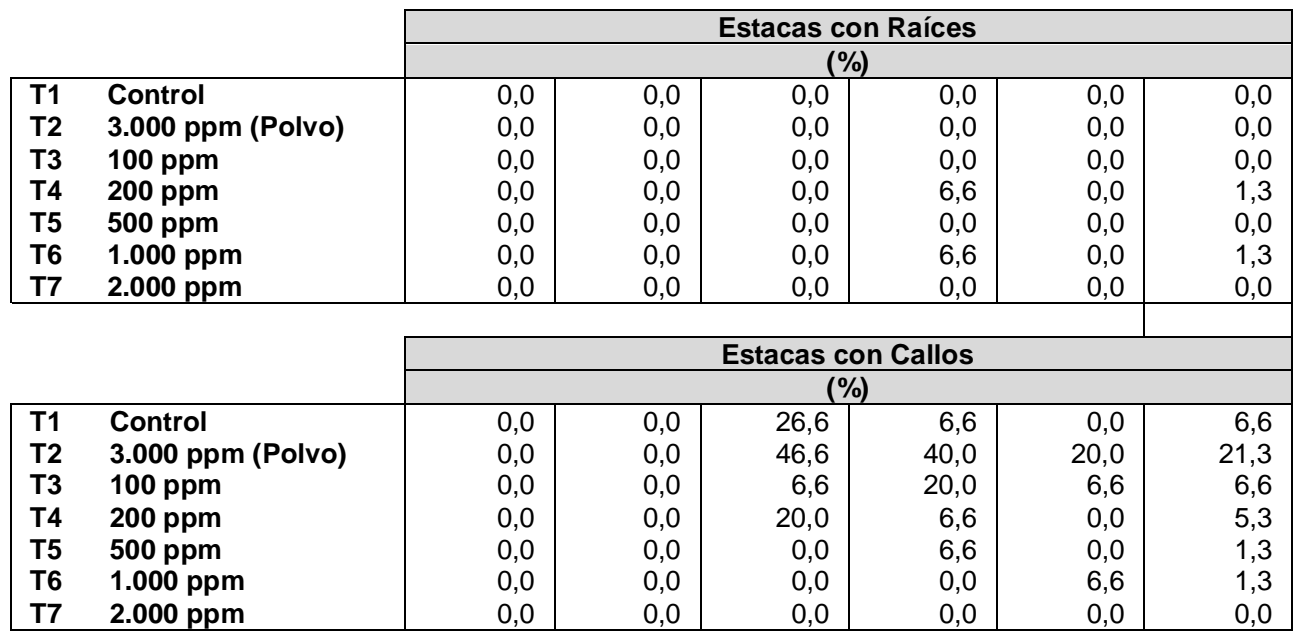


EI AIB es una de las hormonas vegetales más ampliamente utilizadas para estimular la formación de raíces en el cultivo de tejidos vegetales, sin embargo en este caso a distintas concentraciones no tuvo efectos importantes sobre la formación de raíces en estacas de ñire.

En el caso del material procedente del predio Los Mallines, en el Cuadro $\mathrm{N}^{\circ} 5$ se observa que solo un $6,6 \%$ de las estacas evaluadas presentaban la aparición de raíces, esto a los 60 días y a concentraciones AIB de 200 y 1.000 ppm (T4 y T6, respectivamente).

Los tratamientos testigo (T1) y polvo (T2) no mostraron efecto alguno y, respecto de los restantes, no parece haber un efecto de la concentración de AIB dado que tampoco la máxima (T7) y una intermedia (T5) muestran un efecto.

En el caso de la formación de callos, etapa intermedia en la aparición de raíces, el tratamiento T2 con la formulación comercial de AIB en polvo (Acido-3 Indol Butirico 0,3\%) fue el que tuvo mejores resultados a partir de los 45 días. Este tratamiento es el que presenta la mayor concentración de AIB entre todos los evaluados en el ensayo.

Independiente de la concentración hormonal la respuesta en formación de raíces es nula cuando esta es observada en los periodos de tiempo iniciales del ensayo (15 y 30 días).

No obstante, la pobre respuesta puede deberse a la época de colecta de las estacas, asociada al estado fisiológico del material en receso. Para que se formen órganos adventicios las células deben estar en actividad, creciendo y dividiéndose. Por lo que no debe descartarse usar concentraciones mayores de AIB con material colectado en primavera.

\section{RESULTADOS TRATAMIENTOS CON AIB PREDIO VISTA HERMOSA}

\begin{tabular}{|l|c|c|c|c|c|c|}
\hline \multirow{3}{*}{ Tratamientos } & \multicolumn{6}{|c|}{ Evaluación } \\
\cline { 2 - 6 } & 15 & 30 & 45 & 60 & 90 & \\
\cline { 2 - 6 } & \multicolumn{7}{|c|}{ (días) } \\
\hline
\end{tabular}

\begin{tabular}{|c|c|c|c|c|c|c|c|}
\hline & \multicolumn{6}{|c|}{ Estacas con Raíces } \\
\hline & & \multicolumn{6}{|c|}{ (\%) } \\
\hline $\mathrm{T} 1$ & Control & 0,0 & 0,0 & 0,0 & 0,0 & 0,0 & 0,0 \\
\hline T2 & 3.000 ppm (Polvo) & 0,0 & 0,0 & 0,0 & 13,3 & 0,0 & 2,6 \\
\hline T3 & 100 ppm & 0,0 & 6,6 & 0,0 & 13,3 & 0,0 & 3,9 \\
\hline T4 & 200 ppm & 0,0 & 0,0 & 0,0 & 6,6 & 0,0 & 1,3 \\
\hline T5 & 500 ppm & 0,0 & 33,3 & 0,0 & 53,3 & 26,6 & 22,6 \\
\hline T6 & 1.000 ppm & 0,0 & 0,0 & 0,0 & 0,0 & 0,0 & 0,0 \\
\hline T7 & 2.000 ppm & 0,0 & 0,0 & 0,0 & 6,6 & 0,0 & 1,3 \\
\hline
\end{tabular}

\begin{tabular}{|c|c|c|c|c|c|c|c|}
\hline & \multicolumn{6}{|c|}{ Estacas con Callos } \\
\hline & & \multicolumn{6}{|c|}{$(\%)$} \\
\hline T1 & Control & 0,0 & 0,0 & 0,0 & 0,0 & 0,0 & 0,0 \\
\hline T2 & 3.000 ppm (Polvo) & 0,0 & 40,0 & 0,0 & 13,3 & 0,0 & 10,6 \\
\hline T3 & 100 ppm & 0,0 & 13,3 & 0,0 & 6,6 & 0,0 & 3,9 \\
\hline T4 & 200 ppm & 0,0 & 6,6 & 0,0 & 33,3 & 6,6 & 9,3 \\
\hline T5 & 500 ppm & 0,0 & 0,0 & 0,0 & 33,3 & 6,6 & 7,9 \\
\hline T6 & $1.000 \mathrm{ppm}$ & 0,0 & 0,0 & 0,0 & 13,3 & 6,6 & 3,9 \\
\hline T7 & $2.000 \mathrm{ppm}$ & 0,0 & 6,6 & 0,0 & 53,3 & 13,3 & 14,6 \\
\hline
\end{tabular}


Para el material procedente del predio Vista Hermosa (Cuadro $\mathrm{N}^{\circ} 6$ ) se aprecia que la aparición de callos o raíces en el grupo de control es nula en todo el período de evaluación. Respecto de la aparición de callos y raíces, la formulación en polvo indica 10,6\% y 2,6\%, respectivamente.

Resultados más interesantes se aprecian en el tratamiento 500 ppm (T5) con 53,3\% de respuesta en raíces en la evaluación a los 60 días y $33,3 \%$ en respuesta en callos en la misma evaluación, y el tratamiento (T7) que muestra un 53,3\% en formación de callo, sin embargo en raíces solo registra un $6,6 \%$.

No obstante, en ambos casos (T5 y T7) en la evaluación siguiente (90 días) estos porcentajes se reducen fuertemente.

Un efecto similar se observó en un estudio de enraizamiento de estacas de hualo (Nothofagus glauca), en el que tratamiento de estacas con AIB mejoró la respuesta al enraizamiento y también se apreció que las concentraciones superiores generaban una respuesta menor a la formación de raíces (Santelices y Cabello, 2006).

El mismo efecto se observó en un estudio en el cual se aplicó AIB en estacas de guindo santo (Eucryphia glutinosa) en el cual la concentración de 500 ppm fue la que produjo los mejores resultados en relación al potencial de crecimiento radicular con un 53\% (Vidal et al., 2009).

\section{Ensayo de Reproducción por Semillas}

\section{- Análisis Físico de las Semillas}

De acuerdo a Donoso y Cabello (1978) la floración de ñire se produce en el período octubre - noviembre y la fructificación en el período marzo - abril, el tamaño de la semilla es de 3,1 x 3,3 mm, presenta dos cotiledones, es alada, su embrión es rudimentario y el número de semillas por kilogramo se mueve dentro de un rango de 320.000 a 678.000 unidades.

La evaluación efectuada con semillas de un lote de 4.200 unidades procedentes del predio Vista Hermosa indican valores similares para el tamaño $(3,1+/-0,4 \times 3,3+/-0,5 \mathrm{~mm})$ y una pureza de $95,8 \%$. Para el número de semillas por kilogramo la evaluación arroja una cifra de 784.450 (Cuadro $\mathrm{N}^{\circ} 7$ ), valor que está por sobre la parte superior del rango dado por Donoso y Cabello (1978).

\section{Cuadro $\mathrm{N}^{\circ} 7$}

PARÁMETROS FísICOS DE SEMILLAS DE ÑIRE SECTOR VISTA HERMOSA

\begin{tabular}{|c|c|c|c|c|c|c|}
\hline \multirow[b]{2}{*}{ Procedencia* } & \multirow[b]{2}{*}{$\begin{array}{l}\text { Peso lote } \\
\text { (g)** }\end{array}$} & \multirow[b]{2}{*}{$\begin{array}{c}\text { Pureza } \\
(\%)\end{array}$} & \multirow[b]{2}{*}{$\begin{array}{c}\text { Semillas } \\
\left(\mathrm{N}^{\circ} / \mathrm{Kg}\right)\end{array}$} & \multirow{2}{*}{$\begin{array}{c}\text { Peso de } \\
1.000 \\
\text { semillas } \\
\text { (g) }\end{array}$} & \multicolumn{2}{|c|}{ Tamaño } \\
\hline & & & & & $\begin{array}{l}\text { Largo } \\
(\mathrm{mm})\end{array}$ & $\begin{array}{c}\text { Ancho } \\
(\mathrm{mm})\end{array}$ \\
\hline Vista Hermosa & 5,6 & 95,8 & 784.450 & 1,27 & $3,1 \pm 0,4$ & $3,3 \pm 0,5$ \\
\hline
\end{tabular}

*El sitio de recolección pertenece a la comuna de Coyhaique ( $\left.45^{\circ} 48^{\prime} \mathrm{S}-71^{\circ} 54^{\prime} \mathrm{O}\right)$.

${ }^{* *}$ Corresponde al lote evaluado en laboratorio, con un total de $\approx 4.200$ semillas.

El peso de 1.000 semillas es una variable establecida por las normas internacionales para el ensayo de semillas (ISTA) y sirve para tener una idea del tamaño y viabilidad de estas en una especie determinada. Mientras menor sea el peso de una semilla, más pequeño será su tamaño y más baja su viabilidad (Escobar, 2012). El peso de 1.000 semillas de $N$. antarctica de procedencia Vista Hermosa fue de 1,27 g. 
Valores similares fueron entregados por Bahamonde et al. (2013), quienes evaluaron el peso de 1.000 semillas de ñire en diferentes clases de sitio en la Patagonia Argentina, encontrando valores en el rango de $1,1 \mathrm{a} 1,6 \mathrm{~g}$.

Semillas provenientes de una misma procedencia geográfica, de un mismo rodal semillero o huerto semillero, del mismo árbol madre, del mismo fruto, tienen diferentes tamaños, diámetros o calibres. Antecedente importante, ya que semillas de una misma procedencia de mayor calibre germinan más rápido y originan plantas de mayor tamaño que las semillas medianas o más pequeñas.

\section{Capacidad, Energía y Periodo de Energía Germinativa}

La evaluación de geminación en laboratorio efectuada con semillas de procedencia Vista Hermosa entregó los resultados que se indican en el Cuadro $N^{\circ} 8$ para los parámetros que caracterizan la germinación de un lote de semillas determinado, de acuerdo con los tratamientos pregerminativos antes indicados y sobre la base de 4 repeticiones de 50 semillas cada una.

\section{Cuadro $N^{\circ} 8$
PARÁMETROS DE GERMINACIÓN}

\begin{tabular}{|l|c|c|c|}
\hline Tratamiento & $\begin{array}{c}\text { Capacidad } \\
\text { Germinativa } \\
(\%)\end{array}$ & $\begin{array}{c}\text { Energía } \\
\text { Germinativa } \\
(\%)\end{array}$ & $\begin{array}{c}\text { Periodo de } \\
\text { Energía } \\
\text { (Días) }\end{array}$ \\
\hline E1 Testigo sin estratificación & 14,5 & 12,5 & 12 \\
\hline E2 Estratificación 30 días & 16,0 & 14,0 & 13 \\
\hline E3 $\quad$ Estratificación 45 días & 28,0 & 21,5 & 12 \\
\hline
\end{tabular}

En el Cuadro $\mathrm{N}^{\circ} 8$ se puede apreciar una baja capacidad de germinación, que alcanza un máximo de $28 \%$ para el tratamiento $\mathrm{E} 3$, estratificación fría por 45 días.

Resultados similares fueron presentados por Premoli (1991), quien en general observó que las respuestas en germinación de semillas de ñire de diferentes poblaciones (evaluando distintas variables latitudinales y morfotipos) colectadas en los Parque Nacionales Nahuel Huapi y Lanín, Argentina, fue muy baja.

Premoli (1991) indica que varios factores son atribuibles a este fenómeno, entre ellos herbivoría por insectos, en particular del orden Lepidoptera (Gentili y Gentili, 1988); generación de tumores por ataque de bacterias, hongos y/o virus (Braun, 1969); o desarrollo partenocárpico de las semillas por tratarse probablemente de un año de escasa floración (Poole, 1950).

Los bajos valores de germinación obtenidos podrían atribuirse a la temperatura. Nire es una especie que se desarrolla en zonas frías y probablemente necesite temperaturas inferiores a las del laboratorio $\left(18^{\circ} \mathrm{C}-2^{\circ}{ }^{\circ} \mathrm{C}\right)$ para germinar.

En la Figura $N^{\circ} 18$ se grafica la evolución de la germinación acumulada de las semillas durante 30 días de evaluación (ISTA, 2014) de acuerdo los diferentes tratamientos.

En el tratamiento $\mathrm{E} 1$ Control sin Estratificación, durante los primeros días del ensayo las semillas no presentan germinación, esta se manifiesta a partir del día 5 y va incrementándose levemente hasta llegar a un valor de 12,5\% que se logra el día 12 (periodo de energía). Posteriormente la actividad germinativa se hace más lenta y se detiene alrededor del día 19 
cuando alcanza un valor de $14,5 \%$.

En el tratamiento E2 Estratificación 30 días, al igual que en el tratamiento control, la actividad germinativa de las semillas comienza el día 5 del ensayo.

Una tendencia constante se observa desde los días 8 al 13 en donde el porcentaje de germinación aumenta hasta 14\% el día 13 (periodo de energía).

El término del proceso germinativo se encuentra entre los días 18 y 22 y la germinación acumulada al término del ensayo alcanza a $16 \%$, valor superior al tratamiento control.

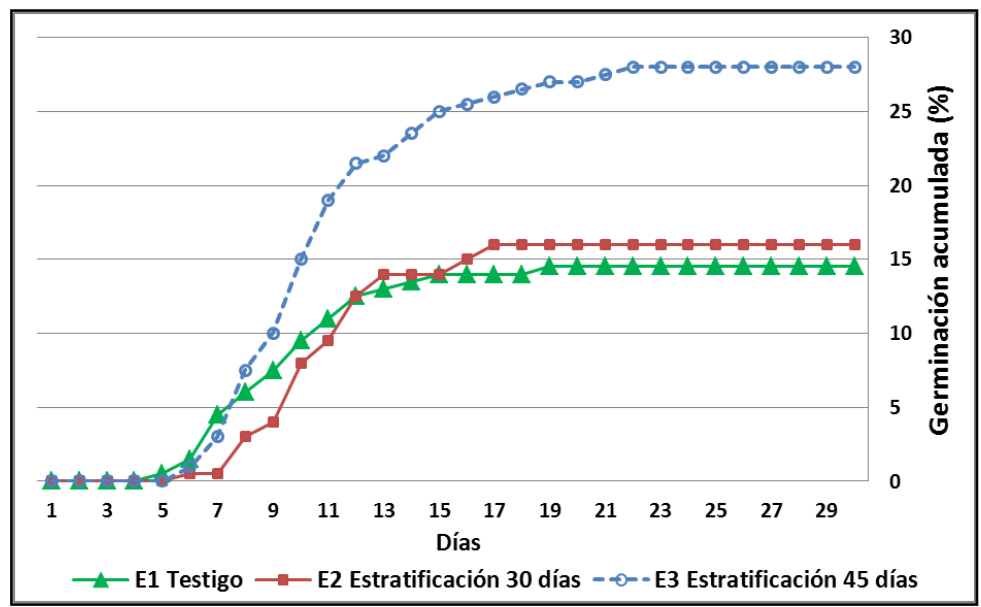

\section{Figura $\mathrm{N}^{\circ} 18$ \\ CURVAS DE GERMINACIÓN PARA SEMILLAS DE ÑIRE ESTRATIFICADAS EN FRIO}

En el tratamiento E3 Estratificación 45 días, al igual que en los tratamientos E1 y E2, la actividad germinativa se inicia el día 5 , logrando la máxima tasa de germinación el día 12, cuando la germinación acumulada llega a 21,5\%. Posteriormente continúa aumentando levemente hasta llegar a $28 \%$ alrededor el día 22 y luego se mantiene sin cambios hasta el final del ensayo. La germinación lograda por este tratamiento E3 casi duplica a la obtenida por E1 y E2, sugiriendo que se podría mejorar aún más usando periodos de estratificación más largos (superiores a 45 días).

La reducida capacidad germinativa de las semillas de ñire fue observada también en estudios de Premoli (1991) en poblaciones argentinas, donde después de la estratificación fría se alcanzó un $18,4 \%$, y en un estudio de Donoso y Cabello (1978) en poblaciones chilenas con un $20,6 \%$.

Esta baja capacidad germinativa de las semillas de ñire puede tener sus orígenes en factores genéticos, como lo demostró el estudio de Quiroga et al. (2005) en tres poblaciones de la especie, mediante electroforesis isoenzimática, estudio que detectó la deficiencia de individuos heterocigotos dentro de estas poblaciones, lo que sugiere la existencia de reproducción entre individuos cercanamente emparentados (endogamia biparental) o de propagación vegetativa dentro de las poblaciones. 
La estratificación fría es un pretratamiento indispensable para romper la latencia de la semilla de una amplia gama de especies de climas templados, permitiendo así mejorar la germinación.

Como ejemplo, para especies del género Eucalyptus de las zonas más frías de Australia, como E. delegatensis, E. nitens, E. regnans y otras, se recomienda estratificación fría húmeda de 3 a 10 semanas (Prado y Barros, 1989).

Los resultados obtenidos con ñire confirman el efecto de la estratificación fría, los valores de germinación obtenidos con el tratamiento E3 (estratificación 45 días) casi duplican a aquellos obtenidos en el control E1 (sin estratificación) y E2 (estratificación 30 días).

Estos resultados sugieren la conveniencia de ahondar en esta investigación con pretratamientos de estratificación algo más prolongados y probablemente con algunas variantes en la temperatura ambiente para las pruebas de germinación.

\section{CONCLUSIONES}

Cuando se quiere propagar especies cuyas semillas presentan en forma natural una baja capacidad germinativa, es preciso encontrar las técnicas apropiadas para mejorar esta capacidad y obtener una mayor cantidad de plantas a partir de las provisiones de semilla disponibles.

Se puede mejorar la capacidad germinativa de las semillas mediante técnicas de pretratamiento para romper su latencia antes de la siembra. Una técnica adecuada para muchas especies de climas templados es la estratificación fría y húmeda por períodos de tiempo variable según la especie.

Una alternativa para especies con semillas de baja capacidad germinativa, aunque de mayor costo, es la propagación vegetativa o asexual. Una técnica habitual para esto es el arraigamiento de estacas bajo ambientes controlados en invernaderos. La capacidad de arraigamiento de estas puede ser estimulada mediante el uso de auxinas $u$ hormonas vegetales, como el ácido indol butírico (AIB), aplicadas en el extremo de las estacas.

Para ñire, especie de los bosques templados del sur de Chile y Argentina, de baja capacidad germinativa comprobada en ambos países, se probaron diferentes tratamientos para mejorar la capacidad germinativa para propagación por semillas y para estimular el arraigamiento de estacas para propagación vegetativa.

Estos estudios se efectuaron en laboratorio en el caso de las semillas y bajo invernadero en el caso del arraigamiento de estacas. Los tratamientos probados corresponden a estratificación fría por 30 y 45 días en el caso de las semillas y aplicación de AIB en seis diferentes concentraciones en el caso de las estacas. En ambos casos se mantuvo un testigo o control sin tratamiento.

Los resultados de germinación obtenidos en laboratorio con una procedencia de semillas de la zona de Coyhaique confirman la baja capacidad germinativa de las semillas de la especie y entregan como mejor resultado el originado con el tratamiento Estratificación Fría por 45 días, con una germinación acumulada a los 30 días de $28 \%$. El resultado de este tratamiento prácticamente duplica a los obtenidos con el testigo (sin estratificación) y con la estratificación fría por 30 días, que llegaron, respectivamente, a $14,5 \%$ y $16 \%$ de germinación, confirmando el efecto positivo de la estratificación fría sobre la capacidad germinativa de ñirre.

Este resultado indica que la producción de plantas por semilla de ñire es posible, pero con un alto insumo de semillas, y las diferencias mostradas por los tratamientos de estratificación hacen recomendable continuar esta línea de investigación incorporando períodos de estratificación 
fría algo más prolongados. Sería conveniente probar otros tratamientos como el remojo en giberelina, procedimiento que aplicado por 24 a 48 horas puede reemplazar a estratificaciones de 30 a 60 días o más y en el cual se usan concentraciones de ácido giberélico en agua de aproximadamente $200 \mathrm{ppm}$.

Los resultados de arraigamiento en invernadero de estacas de dos procedencias de la zona de Coyhaique a los 90 días no muestran una tendencia de importancia en cuanto a la concentración de AIB aplicado a las estacas, aunque sí se aprecia una diferencia más notoria entre las dos procedencias del material vegetal. Aquél procedente de un ñirantal bajo condición edáfica seca en el predio Los Mallines entregó resultados prácticamente nulos en cuanto a formación de raíces, en tanto que el material procedente del predio Vista Hermosa donde el ñirantal que se desarrolla en una condición más húmeda, de mallín, mostró un arraigamiento medio para los períodos de evaluación de $23 \%$.

Dado el costo que involucra este sistema de propagación vegetativa y el rendimiento obtenido, pareciera justificarse solo para reproducir material valioso dentro de un programa de mejoramiento genético y no para programas de forestación de alguna envergadura.

Pareciera haber otras variables de importancia interviniendo en la capacidad de arraigamiento, entre estas podrían estar la edad del material, la época de enraizamiento, la carga genética y las condiciones ambientales durante el arraigamiento (temperatura ambiente del invernadero, temperatura de la cama caliente).

Una continuación de esta línea de trabajo tendría que incorporar, por ejemplo, material rejuvenecido de rebrotes de cepa, diferentes procedencias del material, variantes de temperatura en cama caliente e invernadero, una época más propicia como la primavera cuando el material vegetal no está en receso invernal y tal vez AIB en mayores concentraciones y otras hormonas estimulantes del enraizamiento.

\section{REFERENCIAS}

AGROMET, 2014. Red Agrometeorológica Nacional INIA. Disponible en; http://agromet.inia.cl. (Visitada 28/11/2014).

Alberdi, M., 1995. Ecofisiología de especies leñosas de los boques higrófilos templados de Chile: Resistencia a la sequía y bajas temperaturas. En: Armesto J., c. Villagrán y M. C. Arroyo, (eds.). Ecología de los bosques nativos de Chile. Universidad de Chile. Pp: 279-299.

Alberdi, M., 1987. Ecofisiología de especies chilenas del género Nothofagus. Bosque 8(2): 77-84.

Bahamonde, H.; Peri, P.; Monelos, L. y Patur, G., 2011. Aspectos ecológicos de la regeneración por semillas en bosques nativos de Nothofagus antarctica en Patagonia Sur, Argentina. Bosque 32(1): 20-29.

Bahamonde, H.; Peri, P.; Monelos, L. y Martinez-Pastur, G., 2013. Regeneración por semillas en bosques nativos de Nothofagus antarctica bajo uso silvopastoril en Patagonia Sur, Argentina. Bosque 34 (1). 13 p.

Braun, A., 1969. Abnormal growth in plants. En: Plant physiology, a Treatise, vol. VB, F.C. Steward (Ed.). Academic Press, New York: 379-420.

Cabello, A.; Sandoval, A. y Carú, M., 2002. Efecto de los tratamientos pregerminativos y de las temperaturas de cultivo sobre la germinación de semillas de Talguenea quinquenervia (talguén). Ciencias Forestales. 16 (1-2): $11-18$.

Czabator, F. P., 1962. Germination value: An index combining speed and completeness of pine seed germination. Forest Science 8 (4): $386-396$.

Donoso, C., 1974. Manual de identificación de especies leñosas del bosque húmedo de Chile, Santiago, 168 p. 
Donoso, C. y Cabello, A., 1978. Antecedentes fenológicos y de germinación de especies leñosas chilenas. Ciencias Forestales 1:31-41.

Donoso, C., 2006. Las Especies Arbóreas de los Bosques Templados de Chile y Argentina. Autoecología. Marisa Cúneo Ediciones, Valdivia, Chile. 678 p.

Escobar, R., 2012. Semillas. En; Producción de Plantas en Viveros. Consejo Federal de Inversiones - CIEFAP. 1ra Edición. Buenos Aires. 190 p.

Frangi, J.; Barrera, M.; Puigdefábregas, J.; Yapura, P.; Arambarri, A. y Richter, L., 2004. Ecología de los bosques de Tierra del Fuego. In Arturi M, J Frangi, J. F. Goya eds. Ecología y Manejo de los Bosques de Argentina. La Plata, Argentina. Editorial de la Universidad Nacional de La Plata. 88 p.

Gargaglione, V.; Peri, P. y Rubioc, G., 2013. Partición diferencial de nutrientes en árboles de Nothofagus antarctica creciendo en un gradiente de calidades de sitio en Patagonia Sur. Bosque. Vol 34. no.3.

Gentili, M. y Gentili, P., 1988. Lista comentada de los insectos asociados a las especies sudamericanas del género Nothofagus. Monografía. Academia Nacional de Ciencias Exactas. Fís Nat. 4: 85-106.

Hoffmann, A., 1997. Flora silvestre de Chile, Zona Araucana: árboles, arbustos y enredaderas leñosas. Ediciones Fundación Claudio Gay, Santiago, Chile. 258 p.

INFOR, 2014. Anuario Forestal 2014. Boletín Estadístico № 44. Instituto Forestal, Chile. 159 p.

ISTA, 2014. International Rules for seed Testing. International Seed Testing Association, Bassersdorf, Switzerland. En: https://www.seedtest.org/en/home.html

IREN, 1979. Perspectivas de desarrollo de los recursos de la Región de Aisén del General Carlos Ibáñez del Campo: Diagnóstico del conocimiento de geología y minería. Coihaique, $67 \mathrm{p}$.

Ormazabal, C. y Benoit, I., 1987. El estado de conservación del genero Nothofagus en Chile. Bosque: 8(2) 109120.

Poole, A., 1950. Studies of the New Zealand Nothofagus species. 2. Nut and cupule development. Trans. Roy. Soc. N.Z. 78:502-508.

Prado, J. A. y Barros, S., 1989. Eucalyptus, Principios de Silvicultura y Manejo. Instituto Forestal - Corporación de Fomento de la Producción, Chile. 199 p.

Premoli, A., 1991. Morfología y capacidad germinativa en poblaciones de Nothofagus antarctica (G. Forster) Oerst. Del norte andino-patagónico. Bosque. 12: 53-59.

Quiroga, P.; Russell, R. y Premoli, A., 2005. Evidencia morfológica e isoenzimática de hibridación natural entre Nothofagus antarctica y N. pumilio en el noreste patagónico. Bosque. 26(2):25-32.

Rodriguez, R. Mathei, O. y Quezada, M., 1983. Flora arbórea de Chile. Editorial Universitaria. Concepción, Chile. 408 pp.

Ramirez, C.; Correa, M.; Figueroa, H. y San Martin, J., 1985. Variación del hábito y hábitats de Nothofagus antarctica en el centro-sur de Chile. Bosque 6: 55-73.

Ramirez, C., 1987. El Género Nothofagus y su importancia en Chile. Bosque: 8(2) 71-76.

Romero E. J., 1986. Fossil Evidence Regarding the Evolution of Nothofagus Blume. Annals of the Missouri Botanical Garden 73: 276-283.

Salinas, J.; Acuña, B.; Uribe, A. y Diaz, E., 2013. Producción de árboles y arbustos nativos con fines de restauración de bosques y áreas degradadas en la Región de Aysén: Producción de calafate (Berberis microphylla G. Forst), ciruelillo (Embothrium coccineum J.R. Forst. \& G. Forst.) y fuinque (Lomatia ferruginea (Cav.) R. Br.). INFOR-MINAGRI. Coyhaique, Chile. 80 p.

San Martin, J.; Troncoso, A. y Ramírez, C., 1988. Estudio fitosociológico de los bosques pantanosos nativos de la Cordillera de la Costa en Chile central. Bosque 9 (1): 17-33. 
Santelices, R. y Cabello, A., 2006. Efecto del ácido indolbutírico, del tipo de la cama de arraigamiento, del substrato, y del árbol madre en la capacidad de arraigamiento de estacas de Nothofagus glauca (Phil.) Krasser. Revista Chilena de Historia Natural. 79:55-64.

Soler, R. 2011. Regeneración natural de Nothofagus antarctica en bosques primarios, secundarios y bajo uso silvopastoril. Tesis de Doctorado en Ciencias Biológicas. Facultad de Ciencias Exactas, Físicas y Naturales. Universidad Nacional de Córdoba. Argentina. 144 p.

Steinke, L.; Premoli, A.; Souto, C. y Hedrén, M., 2008. Adaptive and neutral variation of the resprouter Nothofagus antarctica growing in distinct habitats in north-western Patagonia. Silva Fennica 42: 177-188.

Veblen, T.; Donoso, C.; Kitzberger, T. y Rebertus, A., 1996. Ecology of southern Chilean and Argentinean Nothofagus forests. Pages 293-353 in: T. T. Veblen, R. S. Hill, and J. Read (eds.), Ecology and Biogeography of Nothofagus Forests. Yale University Press.

Vidal, R. y Premoli, A., 2004. Variación en Nothofagus antarctica (Forster) Oerst. (Nirre o Nire) En: Donoso C., L. Gallo, A. Premoli \& R. Ipinza (Eds.) Variación intraespecifica en las especies arbóreas de los bosques templados de Chile y Argentina. Santiago: Editorial Universitaria.

Vidal, M.; Delgado, P. y Delgado, J., 2009. Efecto del ácido indolbutiríco en la capacidad rizogénica de estacas de Eucryphia glutinosa. Bosque. 30(2): 102-105. 